\title{
El wakcha héroe o migrante como chakana: una propuesta de clasificación
}

The wakcha hero or migrant as chakana: a classification proposal $\begin{array}{r}\text { John Harvey Valle Araujo } \\ \text { Universidad Nacional Mayor de San Marcos, Lima, Perú } \\ \text { john.valle@unmsm.edu.pe }\end{array}$
ORCID: https://orcid.org/0000-0002-7835-7929

\section{Resumen}

El presente trabajo propone una clasificación del wakcha héroe o migrante en el seno del universo andino, caracterizado por las manifestaciones de una racionalidad mítica propia de las culturas no occidentales. En tal sentido, se recurre a los estudios interdisciplinarios de la tradición oral andina para describir primero la cosmovisión particular del personaje y proponer luego la clasificación de este a partir de su experiencia migratoria. Con ese propósito, se describe, en primer lugar, algunos aspectos propios del universo andino que se corresponden con una visión cíclica del tiempo, cuyo desequilibrio obliga al desplazamiento poblacional. En segundo lugar, se presentan los atributos del wakcha héroe o migrante, en tanto elemento de un todo interrelacionado, según es propio de su cosmovisión, y se establece su rol de chakana en su proceso de rearticulación de su universo. Por último, como resultado de esta investigación, se determina la pertinencia de una propuesta clasificatoria de la categoría wakcha héroe o migrante que toma en cuenta su destino migratorio.

Palabras clave Cosmovisión andina, wakcha migrante, chakana, clasificación

\begin{abstract}
The present work proposes a classification of the hero or migrant wakcha within the Andean universe, characterized by the manifestations of a mythical rationality typical of non-Western cultures. In this sense, interdisciplinary studies of the Andean oral tradition are used to first describe the particular worldview of the character and then to propose the classification of the character based on his migratory experience. For this purpose, it first describes some aspects of the Andean universe that correspond to a cyclical view of time, whose imbalance forces population displacement. Secondly, the attributes of the hero or migrant wakcha are presented as an element of an interrelated whole, according to their own worldview, and their role as chakana is established in their process of rearticulation of their universe. Finally, as a result of this research, the relevance of a classification proposal of the wakcha hero or
\end{abstract}


migrant category that takes into account their migratory destination is determined. Keywords Andean cosmovision, migrant wakcha, chakana, classification

Fecha de envio: 2/2/2021 Fecha de aceptación: 13/5/2021

\section{Introducción}

Entre los trabajos que han contribuido al estudio de la situación social de postergación de las comunidades andinas, desde los inicios de la Colonia hasta el presente, y a los mecanismos de superación de esa difícil posición, destaca el trabajo de John Valle (2012). Creemos que su propuesta de la categoría wakcha resulta valiosa para revalorar la contribución del migrante andino a la transformación sociocultural del país.

El presente artículo pretende ser una contribución al mencionado trabajo, específicamente relacionado con el tipo del wakcha héroe o migrante que el autor ha propuesto. Esta intención se justifica en el hecho de que los diferentes estudios sobre el fenómeno de la migración no han ponderado de manera suficiente la contribución del wakcha héroe o migrante a la formación de identidades sociales tanto en el interior del país como en el extranjero y sus diferentes manifestaciones culturales en los espacios a donde se ha trasladado.

Con ese fin, a manera de hipótesis sostenemos que, por sus particulares características, el wakcha héroe constituye una chakana que articula su aquí-ahora a partir de mecanismos provenientes de un proceso de decantación simbólica coherentes con su cosmovisión, y que el destino final de su desplazamiento es un criterio válido para proponer una clasificación de la categoría. En ese sentido, el presente trabajo persigue dos objetivos puntuales. El primero está orientado a establecer los rasgos distintivos de la cosmovisión del personaje, la cual respondería a una racionalidad mítica caracterizada por establecer relaciones simbólicas, analógicas y metafóricas entre los elementos del cosmos. En este caso, a partir de los atributos de su ser relacional según es propio de la cosmovisión andina, se 
identifican los rasgos del wakcha héroe o migrante como ser doblemente fragmentado. El segundo objetivo, en cambio, se orienta hacia la identificación del wakcha en su rol de chakana, es decir, en su función de eje articulador del nuevo espacio adonde se ha visto obligado a migrar. Sobre esa base, se propone una clasificación de la categoría tomando en cuenta el desplazamiento geográfico al interior o al exterior de la jurisdicción del estado peruano.

Un trabajo de esta naturaleza requiere del concurso de una estrategia multidisciplinaria afín con la complejidad del personaje y su racionalidad mítica. En consecuencia, recurrimos a herramientas que nos facilitan la etnología, la antropología, la filosofía, la historia, la etnolingüística, los estudios de la tradición oral andina, entre otras disciplinas.

\section{La cosmovisión del wakcha héroe y su particularidad}

A partir de la categorización que propone Fontanille (2001) sobre el proceso de descubrimiento de la significación ${ }^{1}$, se puede afirmar que el modo de concebir el mundo en las comunidades andinas y su manera de relacionarse con ese entorno se correspondería con una racionalidad mítica, ya que esta implica una captación semántica del mundo. Esta simbolización del entorno supone la existencia de una instancia que toma una posición y que asume una enunciación para convertir lo impresivo o sensorial en simbólico, mediante relaciones totalizadoras, binarias y analógicas de sus componentes. En la cosmovisión andina, esa instancia la ocupa cada elemento de pacha, el espacio-tiempo, que es concebido como un ente rebosante de vida donde la existencia de cada elemento es dependiente de la existencia de los otros. Precisamente, basado en esa realidad, Estermann (1998) afirma que el pensar del hombre andino en tanto expresión de su racionalidad mítica sería más un pensar del estar que del ser; es decir, para el pensamiento andino el individuo en tanto tal no sería significativo, sino en su condición de ser relacional como cualquiera de los demás elementos de ese cosmos. Ese rasgo justificaría, por consiguiente, el hecho de que, para ser reconocido como miembro de la colectividad en las comunidades andinas el poblador debe someterse a un orden normativo del deber-ser para el bien común ${ }^{2}$.Desde esta perspectiva, podemos afirmar que para las comunidades andinas la realidad es una presencia vivencial simbólica y no conceptual, como sucede en Occidente. Como tal, la realidad se puede re-crear o revelar mediante la celebración cúltica y ceremonial, mas no re-presentar mediante la palabra. Para la racionalidad mítica andina no es la palabra ni el concepto o logos lo que constituye el símbolo primordial, sino la realidad misma en su potencial 
semántico, donde los símbolos se remiten necesariamente los unos a los otros mientras se actualizan constantemente mediante los rituales y la celebración de la vida diaria, que transcurre en un espacio-tiempo particular denominado pacha.

\subsection{La constitución de pacha}

Dejamos establecido que en tanto manifestación de una racionalidad mítica la concepción andina del universo obedece al tipo de relaciones totalizadoras, binarias y analógicas de sus elementos (Fontanille, 2001). En el primer caso ya indicamos que los estudios andinos han corroborado que para estas comunidades cada elemento del mundo resulta significativo por la necesidad de relacionarse con el todo, puesto que de ello depende su razón de ser. Ese hecho pone en evidencia que para esta forma de pensamiento la separación sujeto-objeto, propio de la cultura occidental, resulta absurda; el acercamiento del primero hacia el segundo significa más bien un acto reflejo innecesario, ya que el interés del hombre no es conocer la naturaleza sino reconocerse en ella como símbolo que articula ese todo, según podrá verse luego al tratar al individuo como chacana de ese universo relacional.

Esta forma de relación totalizadora en la cosmovisión andina se evidencia en el significado del vocablo pacha, el cual refiere a la totalidad, entendida esta como la relación entre tiempo, espacio, orden y estratificación (Estermann, 1998). Por lo tanto, pacha haría referencia a un mundo organizado según coordenadas espaciotemporales, pero con la salvedad de que esas coordenadas no establecen estratos o mundos distintos, sino espacios de una misma realidad interrelacionada. Así, los términos hanan pacha, kay pacha y ukbu pacha, que refieren a los estratos de la realidad, perviven en constante relación tensional en una misma coordenada espaciotemporal, pero como dimensiones complementarias (Cotari, 1978). A estos rasgos de pacha, a partir de un análisis de los manuscritos de Huarochirí del padre Ávila, Depaz (2014) deduce que este vocablo polisémico tanto en quechua como en aimara presenta connotaciones cronológicas, espaciales, axiológicas y volitivas. Así, en las expresiones quechuas pachachiri o pachaqariri (referidas a la mujer que ha parido mellizos), pacha ccacnin ("reyr el alva, o abrir, o amanecer"), pachacta hamutani, "pacham ppuchucasacnin, o puchucanayan"("el mundo se quiere acabar"), el vocablo pacha extiende su carga simbólica hacia una matriz genésica asociada al prototipo ontológico de la dualidad, a la astucia o sagacidad aludida en hamutami, a la voluntad del mundo, atributo este característico de un sujeto y no de una cosa que contiene otras, respectivamente. Por consiguiente, el vocablo pacha animiza la 
totalidad dentro de la cual el hombre constituye un nodo semántico como cualquier otro elemento de ese universo relacional.

En cuanto a las relaciones binarias que se establecen entre los elementos del universo en la cosmovisión andina, diversos estudios han dado cuenta de que la primera articulación del mundo según el hombre andino es de carácter dual. En quechua, el vocablo que sintetiza este principio es yanantin, el cual se compone de dos términos con significados opuestos: yana, que refiere a lo oscuro o negro, y yanan, que más bien refiere a lo blanco, unidos por el sufijo vinculante ntin. Por consiguiente, una traducción del vocablo sería "ambos amantes juntos, el amante con su amada o la amante con su amado" (Lira, 2008, p. 581). Sin embargo, en su sentido más amplio el vocablo refiere a la cooperación recíproca o acción complementaria entre los seres que coexisten en el universo relacional andino (Platt, 1986). A su vez, en palabras de Mamani (2019), la categoría yanantin "representa los principios de relacionalidad, complementariedad y reciprocidad. En ellos subyace la idea de los opuestos complementarios que se presentan en la vida para que esta sea buena y se eviten las carencias" (p. 201). Con ello corroboramos una vez más que la idea de individuo en términos occidentales no es concebible en los Andes; más bien, en esta forma de pensar, el elemento básico de organización del universo es la pareja, una relación que hace el ser relacional.

Respecto de las relaciones analógicas que se producen entre los elementos del universo andino, los investigadores han identificado relaciones de correspondencia entre los componentes de ambas dimensiones de una dualidad (Montes, 1984). De esta manera, el cuerpo humano, por ejemplo, deviene síntesis del universo y la presencia del hombre, por su parte, se corresponde con la imagen del dios creador en las ceremonias cúlticas donde se re-crea el mundo. De esta manera, las categorías de Fontanille (2001) que pertenecen al orden de lo sensible para el poblador andino se corresponden con categorías del orden inteligible. Ilustra esta idea la manera en que los pobladores andinos procesan como acto punitivo su experiencia sensorial respecto de un fenómeno de la naturaleza como un temblor, por ejemplo, al relacionarlo con el malestar de la pachamama causado por la ruptura de la reciprocidad debida a ella, para restablecer el equilibrio del cosmos.

Ahora bien, Estermann (1998) propone que el equilibrio en la cosmovisión andina se fundamentaría en cuatro principios que rigen tanto la esfera de lo humano como el orden cosmológico: el de relacionalidad, el de complementariedad, el de reciprocidad y el de correspondencia. Según el primer principio, en el universo andino todo está relacionado con todo; es decir, allí no puede existir ningún 
ente que carezca de relaciones. Por lo tanto, la existencia de los seres en este universo está marcado por un deber-ser relacional. El principio de complementariedad, por su parte, establece que ningún ente en el universo está completo; por lo tanto, no existe de manera aislada. Esto significa que una parte necesaria y complementaria debe integrarse junto con otra también necesaria y complementaria para dar existencia a una entidad plena o complementada. Según el tercer principio, el de reciprocidad, en el mundo andino los diferentes actos en cualquiera de las dimensiones cósmicas de este universo relacional se condicionan mutuamente. Es decir, la acción de un actor será recompensada por otra acción de igual magnitud de parte del receptor.

Según el principio de correspondencia, en el universo andino los distintos elementos se corresponden de manera mutua y bidireccional a través de nexos que pueden ser cualitativos, afectivos, simbólicos y rituales. De esta manera, el símbolo corresponde a lo simbolizado, porque el primero viene a ser una suerte de presentación sui generis del segundo a través del rito. Por este principio puede entenderse que la unión sexual del hombre y la mujer (el símbolo) se corresponde con el acto de fecundar a la Pachamama introduciendo el arado en la tierra primero para luego plantar la semilla (lo simbolizado). Dicho esto, podemos establecer relaciones de correspondencia entre los rasgos de la racionalidad mítica propuestos por Fontanille (2001) y los cuatro principios de la racionalidad andina planteados por Estermann (1998). A las relaciones totalizadoras corresponde el principio de relacionalidad andino, ya que el cumplimiento de este abarca todos los elementos del universo; asimismo, a las relaciones binarias corresponden los principios de complementariedad y reciprocidad, pues en estos casos, su ejecución implica la relación de dos elementos opuestos, pero complementarios; por último, a las relaciones de tipo analógico le corresponde el principio de correspondencia, puesto que a un elemento de una dimensión del cosmos andino le corresponde otro en una dimensión distinta. En conclusión, el concepto pacha refiere a la totalidad espacio temporal mutirelacional.

\subsection{La naturaleza cíclica del tiempo}

Si el vocablo pacha, entre otros sentidos, refiere al "espacio" y "tiempo", se pone en evidencia de que la totalidad del mundo andino es una suerte de red semántica tejida a partir de relaciones espaciotemporales. Más aún si consideramos que la temporalidad para el hombre andino no es cuantificable y sí, en cambio, es de un orden cualitativo dependiente de la trascendencia cósmica de un acontecimiento 
que bien podría estar relacionado con las actividades agrícolas o ganaderas, con las festividades religiosas, o con los ciclos vitales del ser humano (Estermann, 1998). Asimismo, para el hombre andino el tiempo no es unidireccional, como sucede en Occidente, donde existe un principio y un fin que permite establecer una tripartición temporal en pasado, presente y futuro. Más bien, la racionalidad andina es cíclica respecto de su visión del tiempo, de tal manera que el pasado y el futuro se aúnan mediante réplicas simétricas. De esta manera, Montes (1984) pone en evidencia que en quechua solo es posible distinguir el kunan pacha (presente o tiempo de ahora) del ñawpa pacha (vocablo que refiere al mismo al pasado y al futuro), y que se distingue mediante términos como quepa (después, espalda) y ñawpa (antes). Es más, la traducción de ñawpa pacha (pasado) sería "tiempo de adelante" o "tiempo de los ojos", mientras que quepa pacha (futuro) se traduciría como "tiempo de atrás" o "tiempo de la espalda". Para una mejor comprensión de esta concepción del tiempo, Quispe-Agnoli (2006) recurre al reflejo en un espejo: lo que en este se replica es lo que espacialmente se ubica en una posición anterior; sin embargo, el reflejo se produce en la posición posterior al objeto. Es decir, esta réplica del objeto que está atrás se produce adelante, frente a los ojos, tal como queda demostrado en los vocablos ñawi y ñawpa que contienen la misma raíz aunque su significado resulta incluso opuesto.

Por consiguiente, en una racionalidad mítica como la andina, la dinámica que se produce entre pasado y futuro es la misma; dicha situación genera una visión cíclica del tiempo dentro de un proceso que responde al principio general de la relacionalidad del todo, donde cada ciclo se repite periódicamente después de un tiempo de caos que los indígenas denominan pachacuti (Condori y Gow, 1976), concepto importante para considerar en esa visión cíclica del tiempo. En este caso, a la idea de espacio-tiempo connotada por pacha se añade la idea de "regresar" o "volver"; tal es la traducción del verbo kutiy (Montes, 1984). En consecuencia, el vocablo significaría espacio-tiempo que vuelve al caos primigenio para reacomodarse en un nuevo ciclo cósmico como una suerte de nudos en la sucesión de esos ciclos. En estos nudos cada elemento se encuentra en una posición no definida, no determinada, en un estado liminal, de tránsito entre lo que fue y lo que vendrá a ser.

\subsection{La posición del runa en la cosmovisión andina}

A partir de lo dicho en los apartados anteriores, la cosmovisión andina es la manifestación de una experiencia colectiva de la realidad que representa simbólicamente 
el mundo como una red de relaciones mediante distintos ejes cardinales. En esta representación del mundo, a las relaciones del eje vertical comprende el principio de correspondencia; al horizontal, el de complementariedad. En cambio, los dos principios restantes, los de relacionalidad y reciprocidad, en tanto tienen carácter totalizador, están presentes en todos los tipos de relaciones al interior del cosmos andino. En esta red de relaciones marcados por los ejes vertical y horizontal, al punto de intersección en quechua se le denomina chakana, vocablo que viene del verbo chakay, cuyo significado es "cruzar", más el sufijo na, que hace derivar de una raíz verbal un sustantivo (Estermann, 1998). Por lo tanto, chakana sería el cruce, la transición, la puerta, el puente o nexo entre dos dimensiones cósmicas. Es más, podemos afirmar, también, que la chakana es el punto que articula el todo y que da sentido a la red de relaciones del cosmos para, a su vez, tener sentido como tal. Así, existen múltiples chacanas: los puntos centrales de las comunidades, las apachetas, el hombre, entre otros.

Según esta explicación, como una más de las chakanas del universo andino, el runa, que según Landeo (2010) "forma parte de un ayllu, trabaja el mismo sus tierras, se comunica en runa-simí, participa de las fiestas del ayllu, chaccha coca y practica las creencias religiosas de la comunidad. Pero principalmente ostenta esta categoría porque así lo reconoce otro runa” (p. 85$)^{3}$, deviene en un nodo más de esa red de relaciones y su posición obedece, básicamente, a la función que debe desempeñar en el conjunto: la actualización simbólica del cosmos mediante el rito. De esta manera, como chakana, el runa vincula el hanan pacha con el kay pacha mediante las labores agrícolas. Por lo tanto, el runa constituye un nodo de múltiples relaciones.

En el kay pacha, el runa es elemento relacional dentro de un grupo de individuos denominado ayllu, que, en tanto un principio de organización social fundamentado en las relaciones parentales de los miembros (Golte y Adams, 1990), es base de la identidad de aquel. Al interior de ese grupo, la vinculación entre los runas es un acto de obediencia al orden cósmico, ya que del acatamiento de los principios que rigen en aquel depende la existencia. En ese sentido, la categoría runa no puede ser definida desde una óptica ontológica o gnoseológica; su constitución más bien es de carácter existencial validada por el principio de la relacionalidad con el todo.

En síntesis, el hombre andino constituye una chakana que articula el orden cósmico en función de su relacionalidad con la totalidad, lo que le confiere su identidad. Claro que ello no significa la ausencia de runas que dejan de serlo 
precisamente por la ruptura de algunos de los principios que rigen ese universo multirelacional. A uno de estos seres, precisamente, nos referiremos en el siguiente apartado: el wakcha.

\section{Los atributos del wakcha migrante}

La configuración del wakcha está íntimamente vinculada con la ruptura del orden cósmico, con la alteración de esa red de relaciones que es pacha. Según Valle (2012), el wakcha refiere a

una categoría andina que alude al runa huérfano de padre y madre, en un principio y, según Gonzales Holguín, al runa que no posee bienes. [...] Es un personaje cuya existencia se ve constreñida a la marginación o la marginalidad. No puede reciprocar porque no posee bienes [materiales] [...]; ni puede ser complemento de nada porque es "huérfano de huérfanos" y, por lo tanto, está incompleto; por último, como efecto de las carencias anteriores, tampoco puede relacionarse con los demás, ni siquiera con los dioses. Sería, a decir de Estermann (1998), "en el fondo 'vano' [...] e 'incompleto' (un ente a medias) (p.39).

De la definición colegimos que el runa o el poblador andino enmarcado en una racionalidad mítica se convierte en wakcha cuando, debido a la interferencia de cualquier circunstancia ya sea provocada por él mismo o por un tercero, pierde su función de chakana. Al respecto, tanto Arguedas (1961/1994) como Lienhard (1993) proponen que el sentido de la orfandad del wakcha rebasa la muerte de padre y madre, porque para el hombre de los Andes también significa la pérdida del amparo divino, la ruptura con el ayllu y con los paisanos. Por consiguiente, carente de los nexos que lo integren a ese universo relacional, el wakcha deviene un ser fragmentado, un sujeto escindido, característica que analizamos en el siguiente apartado.

\subsection{La escisión del wakcha héroe como rasgo existencial}

El rasgo relacional del runa resulta análogo con la imagen del hombre moderno caracterizada por la valoración del discurso consciente racional en la construcción de sí mismo como sujeto. La constitución del runa como tal se produce en un universo estable, fijo, que respeta un orden, el orden que le dictan los principios de su racionalidad mítica. Sin embargo, cuando ese ser relacional deja de serlo debido a situaciones que alteran la relacionalidad de su universo se verá impedido de cumplir por lo menos tres de los cuatro principios que rigen su cosmovisión 
en su allá-entonces. Como indica Valle (2012), al no poseer bienes materiales, no podrá reciprocar con los demás; al estar incompleto, se verá impedido de ser complemento de otro; finalmente, por haber sido aislado respecto de la comunidad, tampoco podrá relacionarse con los demás. En cambio, en relación con el cuarto principio, al contar con una riqueza de tipo moral, la figura del wakcha se correspondería con la divinidad poderosa que reestablece el orden cuando este ha sido roto.

Ahora bien, esta situación del wakcha es análoga a la que ocurre cuando la cadena de significantes experimenta una ruptura, lo cual, según apunta Jameson (1991) desde una óptica psicoanalítica, es la causa de la esquizofrenia. Este crítico y teórico literario estadounidense, tomando como punto de partida esa relación entre el defecto lingüístico y la mente del sujeto esquizofrénico, deriva una interesante conclusión dual: por una parte, la identidad del sujeto resultaría de una unificación temporal del pasado y el futuro con el presente; por otro lado, esa unificación temporal sería una función del lenguaje en su movimiento dentro de su círculo hermenéutico a lo largo del tiempo. En cambio, cuando "esa relación se rompe, cuando se quiebra uno de los eslabones de la cadena de los significantes, estamos en presencia de la esquizofrenia en su forma de desechos de significantes distintos y no relacionados entre sî"Jameson (1991, p. 49).

Significa pues que la ruptura de la cadena de significantes reduce al sujeto esquizofrénico a una serie de "presentes puros" desconectados del pasado y del futuro, a una retahíla de significantes que, impedidos de relacionarse entre sí, generan una suerte de "vaciedad semántica" y de cierta "relativización ontológica”, un sujeto escindido o fragmentado. Por consiguiente, a semejanza del sujeto esquizofrénico, si el runa pierde su capacidad de relacionalidad, su deber-ser (el equivalente a la constitución ontológica en Occidente) también se relativiza, por lo que deviene en un equivalente del sujeto escindido occidental. Es decir, al aislarse de los demás componentes de su universo, el runa se convierte en un significante flotante, en un huérfano cósmico, en un wakcha.

En su propuesta de clasificación del wakcha, Valle (2012) denomina a este tipo como wakcha héroe o migrante, cuya heroicidad radicaría en la conservación de su memoria, riqueza de carácter moral, a pesar de (o precisamente por eso) la hostilidad del nuevo entorno dominado por la escritura adonde se ha trasladado. En consecuencia, los distintos movimientos migratorios encerrarían una carga semántica que excede la idea simple del traslado geográfico al interior o al exterior del territorio peruano, según fuera el caso, de esa riqueza moral del indígena; 
la migración devendría "en trasplante, en una aclimatación mediante una suerte de decantación y asimilación de elementos exógenos con el fin de generar una realidad que conserve tanto lo andino como lo criollo"(Valle, 2012, p. 61).

Cabe señalar que la aplicación de la propuesta de Jameson acerca del sujeto escindido de la posmodernidad occidental a la condición del wakcha migrante ya ha sido avizorada por la crítica. En un trabajo sobre la novela El zorro de arriba y el zorro de abajo de Arguedas, Cornejo (2004) identifica en el migrante algunos rasgos similares a los del sujeto posmoderno del crítico norteamericano. Sostiene el crítico peruano que

el migrante estratifica sus experiencias de vida y que ni puede ni quiere fundirlas porque su naturaleza discontinua pone énfasis precisamente en la múltiple diversidad de esos tiempos y de esos espacios y en los valores y defectividades de los unos y los otros. La fragmentación tal vez sea su norma (p. 48).

Asimismo, afirma este crítico peruano que el migrante nunca deja de serlo del todo:

aunque se instale definitivamente en un espacio y lo modifique a su imagen y semejanza, porque siempre tendrá detrás su experiencia fundante y una casi imperturbable capacidad para referir la existencia en relación [con] la índole de las estaciones y de las fronteras que hubo de conocer para instalarse en un lugar que probablemente lo fascina tanto como lo aterra (p. 55).

De tal manera sucede entonces con el wakcha migrante que deviene en víctima de una doble escisión: no solo ha experimentado la fragmentación de su ser en las urbes modernas adonde se ha trasladado; previamente, también, se ha visto fragmentado al romper sus vínculos físicos con su allá-entonces vinculado al calor de los afectos familiares en su lugar de origen. Así, el wakcha se constituye en un ser escindido entre su aquí-ahora — su forasterismo- y su allá-entonces - su "autoctonismo"-; es un símbolo de la anomalía dentro del universo andino, por lo que pertenece al orden de lo ambiguo e inclasificable, a un estado liminal, entendido este como estado intermedio o de transición entre dos etapas, y que se caracteriza por la indeterminación, la ambigüedad y la hibridez. Sin embargo, aunque este wakcha migrante se caracteriza por su descentramiento, por sus profundas contradicciones que son la causa de su inestabilidad identitaria, a 
diferencia del sujeto esquizoide de la cultura occidental no muestra tendencias autodestructivas. Por el contrario, como ya se indicó, en tanto símbolo que se corresponde con una divinidad andariega, a manera de un pachacuti personal y colectivo revierte esa condición con sus recursos propios y con los que adquirió en el nuevo espacio.

\subsection{El wakcha-héroe como chakana}

Dejamos establecido que el wakcha es símbolo correspondiente de la poderosa divinidad prehispánica que, disfrazado de mendigo, se traslada a lo largo de la tierra como portador de la justicia cósmica dispuesto a castigar a las poblaciones que hayan violado las normas de convivencia. Generalmente, su castigo consiste en transformar en lagos o lagunas, o en bosques de piedras a las poblaciones opulentas que han dejado de reciprocar con los menos favorecidos. Desde esta perspectiva, se puede afirmar que la existencia del wakcha es un ritual, una constante actualización del dios trotamundos de los mitos que se traslada portando en secreto su poder transformador (Morote, 1988).

Como esta divinidad, entonces, el wakcha héroe o migrante desciende a los llanos costeños o amazónicos y transforma el orden de las ciudades (Golte y Adams, 1990), y las recrea, las refunda (Matos, 2004). Para esa labor transformadora, si bien el wakcha no cuenta con la riqueza material para hacerla efectiva, su amplio conocimiento de los principios que rigen el equilibrio de su allá-entonces, la confluencia en el nuevo espacio de otros seres como él con quienes va a interactuar y la adquisición de nuevos saberes propios del nuevo espacio adonde se trasladó, su aquí-ahora, lo convierten en un ser poderoso para producir el cambio subvirtiendo un orden que le ha negado su constitución como persona. De manera análoga con el proceder de esa divinidad andariega que se desplaza para castigar la alteración del orden y restablecerlo para dotar de sentido al universo, el wakcha migrante recobra su estatuto anterior en su aquí-ahora, siempre sobre la base de su riqueza moral obtenida en su allá-entonces. Es decir, en tanto personaje que rearticula el orden cósmico al ser la síntesis de las contradicciones tensionales de su nuevo universo, este wakcha recobra su estatuto simbólico interdimensional de chakana en su aquí-ahora y sus prácticas vuelven a corresponderse con las relaciones interdimensionales del cosmos. Es decir, en tanto nodo semántico que sintetiza el universo, el wakcha héroe o migrante traduce la totalidad para hacerla accesible a nivel micro cósmico. 


\section{Clasificación del wakcha héroe o migrante}

Establecimos que la heroicidad del wakcha radica en la conservación de su memoria, riqueza de carácter moral, a pesar de (o precisamente por eso) la hostilidad del nuevo entorno dominado por la escritura adonde se ha mudado. De esa manera, los movimientos migratorios resultan más significativos que un simple traslado de la sierra a la costa, o a la selva, según fuera el caso, de esa riqueza moral del indígena. Valle (2012) sostiene que la migración deviene "en trasplante, en una aclimatación mediante una suerte de decantación y asimilación de elementos exógenos con el fin de generar una realidad que conserve tanto lo andino como lo criollo" (p. 61), lo moderno como lo tradicional. Precisamente, esos elementos estarán condicionados por el destino final del desplazamiento, criterio que tomaremos en cuanta para la distinguir los tipos de este wakcha héroe. Así, consideramos dos grupos: la migración interna y la migración externa.

\subsection{El wakcha migrante interno}

Si bien los desplazamientos de las poblaciones indígenas en nuestro país se han sucedido desde tiempos prehispánicos, los que se produjeron en el siglo XX despertaron el interés de la academia debido a su trascendencia histórica y su impacto en la transformación sociocultural del Perú. La mayor parte de estudios sobre el tema han dado mayor relevancia al desplazamiento poblacional procedente de la sierra con destino a la costa, específicamente la ciudad de Lima. No obstante, el fenómeno migratorio peruano no solo se produjo desde el interior hacia las ciudades costeras; también debe considerarse el desplazamiento poblacional hacia la llanura amazónica y hacia las capitales regionales. Es más, desde la década de 1980 la migración hacia el exterior del país también ha sido significativa.

\subsubsection{El wakcha migrante interno de las ciudades costeras}

Sin duda, el desplazamiento humano de la sierra a la costa, básicamente a la ciudad de Lima, ha sido el más significativo del siglo XX, pues causó la transformación de las ciudades costeras más importantes a nivel sociocultural y sobre todo en el aspecto económico. Bértoli y Portocarrero (1968), en una tesis temprana sobre el tema, sostenían que el fenómeno se debió a cinco factores: el mayor nivel educativo de los integrantes de la sociedad moderna acetada en la capital que causaba una idealización relacionada con el progreso en los provincianos, las mayores facilidades de transporte para el traslado, el aumento del alcance de los medios de difusión de masas y las necesidades de relocalización de mano de obra 
en vista de la crisis de la agricultura. Desde entonces, las olas migratorias se han sucedido a lo largo del siglo XX, incluso en el siglo XXI, motivadas aun por los mismos factores (Rodríguez, 2015), excepto en los 80, cuando se agregó la guerra interna, que obligó a la población rural andina y amazónica a trasladarse hacia las ciudades costeras, especialmente Lima (Yamada, 2015) escapando de la violencia.

Para eso, el wakcha migrante tuvo que aprender los códigos culturales del criollo citadino con el fin de adaptarse a esa realidad excluyente, para luego, desde dentro, transformarla, según dejamos establecido, pero sin renunciar a sus códigos culturales de origen. En este caso, uno de los instrumentos transformadores de los que se apropió este tipo de wakcha migrante fue la tecnología de la escritura, la cual le había sido negada desde los tiempos coloniales, salvo en contados casos de indígenas vinculados a la nobleza o el de los cronistas indígenas. Con esa apropiación del indígena, su memoria, que antes fue portadora de su cultura, ahora se veía enriquecida con los mecanismos de la escritura; su cuerpo, que antes fue un significante de la comunicación oral, ahora devenía en símbolo de restitución de la oralidad mediante el uso de las manos para registrar las grafías sobre el papel. Con ello, según De Llano (2001), la escritura dejó de ser la transmisora exclusiva de la historia oficial y se convirtió más bien en la traductora de la heterogeneidad, en un punto de enlace pero también de choques permanentes entre las múltiples concepciones de la cultura; es decir, la escritura devino en una chakana más de ese universo. Este dominio de la tecnología escritural modificó la realidad y el otro subversivo ahora devino en ego mediante un pachacuti personal; el otro ha dejado de ser enigmático y ahora espera reciprocidad de ego para la construcción común de la cultura (Valle, 2012).

Culturalmente también este tipo de migrante ha logrado andinizar las principales ciudades costeras, ya que en tanto símbolo que se corresponde con la figura del dios andariego, al trasladarse geográficamente también acarrea con su memoria que es su instrumento de poder. Golte y Adams (1990) afirman al respecto que no se puede entender la suerte que corre un migrante en Lima si antes no comprendemos "la sociedad local de la cual proviene y los nexos que los originarios de un pueblo establecen entre sí en su proceso de inserción en la economía y sociedad urbanas" (p. 74). Por su parte, Matos (2004) sostiene que

Este provinciano migrante, serrano, especialmente rural y de comunidades tradicionales, poblador de otro Perú marginado y pobre, demostró en su gesta de cinco décadas que mantenía pujanza andina. Urbanizaron la costa en toda su extensión, Lima de preferencia. Se impusieron 
y lograron mejores niveles de vida y de bienestar en medio de la crisis que nos agobia. De no haber migrado otro sería el rostro del Perú. Ahora, ellos, en su pobreza y en su bonanza, apoyan y ayudan a los que quedaron y abren nuevos horizontes al destino futuro del Perú (p. 132).

Ha sido precisamente esa capacidad de urbanizar a su modo las ciudades costeras, esa pujanza andina lo que demuestra su correspondencia con el poder divino del dios migrante que transforma la geografía y los pueblos para restablecer el equilibrio cósmico (Morote, 1988). Esa pujanza evidencia el restablecimiento de su constitución de chacana como poderosa síntesis de la multidimensionalidad del universo. Fuller (2002) sintetiza este proceso en los siguientes términos:

la ola de migrantes andinos que procedían fundamentalmente del ámbito rural construyó otra 'institucionalidad' en los límites del modelo de modernización deficiente propuesto por el Estado, y en el cual ellos no tenían un lugar. Una ola indigenista renovada de autores que provenían de las ciencias sociales identificó la creciente informalización de la economía y la organización de pueblos jóvenes con el surgimiento de una nueva cultura peruana (p. 435).

\subsubsection{El wakcha migrante interno de los llanos amazónicos}

Como en el caso anterior, en este el motivo del destierro también ha sido la busca de mejoras económicas. De manera similar a lo ocurrido en la costa, las ciudades de la región fundadas durante la Colonia como Moyobamba (1540), Lamas (1656), Rioja (1772), Tarapoto (1782); las ciudades fundadas durante la República: Pucallpa (1888), Madre de Dios (1912) experimentaron una importante transformación cultural y económica debido a la migración de los pobladores andinos. Es más, muchas ciudades y centros poblados que hoy son pujantes centros económicos fueron fundados por migrantes, como es el caso de la ciudad de Nueva Cajamarca (1970) en la región San Martín (San Román, 1994).

En el caso del nororiente, los desplazamientos poblacionales procedieron, básicamente, desde las regiones altas de los departamentos de La Libertad, Cajamarca y Amazonas. Si bien este fenómeno venía ocurriendo desde muchas décadas atrás y generalmente motivado por la leva del Ejército para resguardar la frontera con Colombia (San Román, 1994), fue con la construcción de las vías de penetración que el desplazamiento poblacional a la Amazonía se masificó. El principal móvil de estos desplazamientos poblacionales era la necesidad de poseer tierras en un contexto de hacendados que dominaban la economía en las 
zonas altoandinas en detrimento de las comunidades. Durante los años 60, el poblador andino comenzó la colonización masiva de la Amazonía básicamente para explotar los recursos forestales y establecer áreas de cultivo. Para la década de 1970, con el descubrimiento de yacimientos petrolíferos, se produjo una segunda ola migratoria hacia los llanos amazónicos en busca de mejoras laborales. En cambio, según señala Limachi (2009), desde los 80 hasta inicios de los 90, durante el auge del cultivo de la coca y del narcotráfico, se acentuaron aún más los desplazamientos poblacionales de la sierra hacia los centros de mayor producción cocalera; lamentablemente, en este caso, también se trasladó de la sierra a la selva la violencia terrorista de Sendero Luminoso y del MRTA.

Un hecho significativo de esta situación ha sido el cambio en la percepción de los naturales, tanto criollos como nativos, respecto del migrante andino a quien despectivamente llamaban "maldito shishaco". En la actualidad, muchos de esos criollos, motivados por una visión progresista de la Amazonía, han tomado conciencia del importante rol del serrano o shishaco para el crecimiento económico de la región, básicamente dedicándose a labores agropecuarias y forestales en las primeras décadas, para posteriormente incursionar en algunas actividades agroindustriales (Valle, 2012). Una vez en su rol de chakana, el migrante ha transformado la cultura amazónica.

\subsubsection{El wakcha migrante interno a las capitales regionales}

Esta forma de desplazamiento interno no ha recibido la debida atención de las ciencias sociales en el siglo XX, como sí sucedió con los dos casos anteriores. Esta forma de migración ha ocurrido siempre, aunque a menor escala, motivada por las mismas razones, ya que en las zonas rurales la población ha tenido menores oportunidades de progreso debido a la crisis de las actividades agropecuarias tradicionales. Este desplazamiento poblacional ha crecido en consonancia con la importancia que fueron cobrando como centros de administración las capitales de regionales. En ese sentido, el proceso de descentralización de las políticas gubernamentales del Estado ha contribuido a la atracción de la población rural hacia estos centros regionales de gobierno (INEI, 2015).

En ese sentido, como el proceso de descentralización ha sido nulo o lento durante gran parte del siglo XX, la migración interna regional se aceleró en la década de 1990, con la implementación del modelo económico neoliberal del gobierno de Fujimori (1990 al 2001). Informa la Contraloría General de la República (CGR, 2014) que, aunque el gobierno previo de Alan García (1985-1990), 
en su último año, en el difícil contexto económico, político y social y de violencia terrorista, ya había emprendido un proceso acelerado de regionalización, fue necesario un cambio de Constitución Política para sentar las bases del proceso. Como consecuencia de ello, las regiones se convirtieron en motores de inversión, lo que ha generado desplazamientos poblacionales en múltiples direcciones al interior del país, según la ejecución de obras (CGR, 2014). Pero, adicionalmente a la búsqueda de mojeras laborales que motivan esta migración, el área educativa ha sido factor determinante. Con la implementación de la Ley Orgánica de Educación Pública 9359 de 1941, que establecía cuatro niveles de educación (inicial, primaria común, secundaria común y técnica, y superior), mayor población tuvo acceso a estos (Chiquilín, 2011). En efecto, con la creación de nuevos centros de educación común o técnica, de centros superiores de estudios, técnicos o universitarios, en las capitales regionales, las familias que no cuentan con los recursos económicos necesarios para brindarles a sus hijos una educación superior en algún centro superior en Lima optan por enviar a sus hijos a esos centros regionales o por trasladarse a las periferias de estas ciudades donde construyen sus viviendas de manera informal, tal como ocurre con la ciudad de Lima (CGR, 2014).

\subsubsection{El wakcha migrante interno del retorno al terruño}

Otra variante del wakcha héroe o migrante interno es el migrante de la primera o segunda ola que decide regresar a su lugar de origen después de décadas de ausencia. En este caso, lo que fue su allá-entonces evocado con nostalgia permanente desde su ancestral memoria y aparentemente retorna a su estatuto inicial; sin embargo, en la medida en que lleva consigo los nuevos códigos que ha asimilado en lo que fue su aquí-ahora, resulta un ser extraño marcado por su forasterismo ahora en el espacio que él no ha dejado de considerar como suyo. Esta condición resulta mucho más desgarradora porque será la evidencia de que su nostalgia, su "soledad cósmica", lejos de desaparecer con el regreso, se acentúa (Cornejo, 2004). Un caso significativo que ilustra esta condición del wakcha héroe es el caso de Lurgio Gavilán (2017).

Los recuerdos son como un viaje a través del tiempo infinito, es volver a la tierra que te vio llorar, crecer y reír. Caminé por estos lugares, subí por esas montañas de Tambo, a pie, a veces descalzo o con zapato de jebe, y ahora estoy aquí mirando las huellas que dejé, tal vez cuando muera ya no venga mi alma porque ya estoy repasando los caminos andados aunque todavía esté vivo. Siento que se me ha ido el tiempo muy rápido. 
Entonces me vienen el deseo de volver la mirada atrás y recordar las cosas pasadas que permanecen tatuadas. Así pienso mientras miro, los pueblos, el horizonte, los ichus meciéndose con el viento de la mañana (pp. 189-190).

Tal vez explique la acentuación de ese forasterismo en este wakcha héroe la fragmentación de pacha en su experiencia vital en el espacio ajeno donde ha vivido. El traslado geográfico implica también la escisión entre los dos componentes del concepto, vale decir, espacio y tiempo; el desplazamiento geográfico de su allá hacia su aquí sentará también, irremediablemente, la diferencia entre su entonces y su ahora. El tiempo del retorno (su ahora), aunque el individuo se encuentre nuevamente en lo que fue su allá de migrante, será irreconciliable con el tiempo de su memoria (su entonces).

\subsubsection{El wakcha migrante externo}

Un segundo grupo de wakcha héroe o migrante está conformado por los que salieron fuera del territorio peruano. En este caso, el proceso se acrecentó exponencialmente desde finales de los años 80 , cuando la guerra interna y la crisis económica complicaron la situación del país, según informan la Organización Internacional para las Migraciones (OIM), el Instituto Nacional de Estadísticas e Informática (INEI), la Superintendencia Nacional de Migraciones (Migraciones) y el Ministerio de Relaciones Exteriores (RREE) (OIM et al., 2018). Según dicho informe, de 1990 a 2017, alrededor del 10\% de la población peruana ha migrado al exterior y no ha retornado. La cifra exacta que ofrece este organismo es de 3089123 personas. Por lo general, los nacionales emigran a Norteamérica, Europa, Asia y países vecinos de Sudamérica. Según estos destinos finales del migrante externo, propondremos dos tipos.

\subsubsection{El wakcha migrante de países hispanoparlantes}

$\mathrm{El}$ informe de la OIM et al. (2018) indica que alrededor del 73\% de la población migrante se desplaza a países de habla hispana de preferencia. Entre estos, los que albergan a la mayor parte son Chile con el 28,7\%, Bolivia con 15,2\%, mientras que Ecuador ocupa el tercer puesto con 11,6\%; a su vez, entre los países hispanos no fronterizos, España alberga al 8,2\% de los migrantes peruanos, mientras que Argentina alberga al 3,8\%. Podríamos deducir que la preferencia por estos países se debe a las cercanías socioculturales con raíces históricas comunes relacionadas con la cosmovisión andina además del idioma. Estos datos resultan 
relevantes porque el choque cultural del migrante no será tan dramático, ya que en cierto sentido podríamos equipararlo con la experiencia del traslado de la sierra a Lima. Al respecto, para el caso de los migrantes andinos peruanos en Chile, Márquez y Correa (2015) concluyen que el desarraigo deviene en posibilidad de fortalecimiento de los lazos sociales, pero también de construcción de identidad siempre inacabada, flexible a la diversidad cultural.

\subsubsection{El wakcha migrante de países no hispanoparlantes}

Si bien es cierto que la gran mayoría de estos migrantes no proceden de poblaciones andinas directamente, sí son descendientes de primer o segundo grado de los migrantes andinos a la capital. Entre estos migrantes que prefieren destinos no hispanos, según el informe en cuestión, Estados Unidos ocupa el primer lugar, pues alberga al 30,9\% de migrantes. En este país, las ciudades de residencia preferida de los peruanos son Nueva Jersey, Nueva York, Miami y Los Ángeles. El segundo lugar lo ocupa Italia con un 10\%, seguido de Japón con 3,9\% (SNM, 2018).

Un estudio sobre este tipo de migrante, aunque centrado en el caso de los migrantes peruanos en Estados Unidos, ha sido realizado por Ulla Berg (2016), quien ha hecho un seguimiento a migrantes de comunidades rurales del valle del Mantaro en la ciudad de Huancayo, en Lima y luego en ciudades norteamericanas. En este trabajo la autora realiza un análisis de lo que denomina "experiencias de la movilidad transnacional" del Quino Suyo, conformado por migrantes andinos en el extranjero que han ganado cuotas de poder debido a las remesas que envían a sus familiares, a su importancia numérica en caso de elecciones nacionales y a su elocuencia ante el Estado como para exigir algunos derechos.

Entre sus conclusiones, la autora destaca que el movimiento migratorio se debió a la guerra interna protagonizada por movimientos terroristas como Sendero Luminoso y el Estado. También toma en cuenta la importancia de la flexibilidad del capital y la diferenciación de los mercados laborales globales para la migración peruana. Pero resalta al mismo tiempo que si bien la globalización amplió las posibilidades de movilidad de la mano de obra, también acentuó la separación y segregación de las minorías en los países de destino. Ante una situación semejante, en el caso de los peruanos, los migrantes en suelo norteamericano se han visto en la necesidad de actuar en la producción de su propia circulación, para lo cual deben involucrarse en prácticas comunitarias y performativas que emplean recursos y señales visuales, retóricas y materiales procedentes de su allá-entonces, 
con el fin de "producir no solo un conjunto de relaciones sociales sino también un conjunto de imágenes de quiénes son y cómo les gustaría ser vistos en medio del contexto de relaciones y campos sociales" (Berg, 2016. pp. 275-276).

\subsubsection{El wakcha migrante externo del retorno}

Muchos de estos han decidido retornar al país y al seno del hogar debido a la bonanza económica por la que atraviesa el país. En muchos casos, pese a que siempre enviaron sus remesas, se ha producido una sensación de extrañeza con la familia, específicamente con los hijos a quienes dejaron cuando estos todavía eran niños. Sobre ese retorno, según el informe de migración de la OIM (2018, p. 65), desde 2010 la cantidad de migrantes que regresaban al país se fue incrementando a un ritmo del $8 \%$ anual.

Como en el caso del regreso interno, también en estos el acercamiento entre el aquí-ahora y el entonces-allá del wakcha se limita solo al aspecto geográfico; culturalmente ha experimentado una serie de cambios motivados por la influencia de la cultura occidental. Con ello, este tipo de huérfano descubre que su entonces-allá ha pasado a la dimensión de lo irrecuperable, de lo utópico, como una suerte de arcadia perdida, condición que acentúa el sentimiento de nostalgia, motivo para que experimente una doble escisión: la fragmentación de su ser fragmentado. En su caso, la memoria — su riqueza moral—, que era anclaje para su existencia, ya no le pertenece. De esa manera, este wakcha deviene en eco confuso, en significante huérfano que flota en la inconmensurabilidad de las semiosferas posmodernas.

Finalmente, considero necesario llamar la atención sobre este tipo de wakcha migrante, ya que resulta problemático para nuestra propuesta de clasificación, la cual está basada en la recuperación del estatuto de chakana para revertir su condición de postergación. Este migrante del retorno, tanto interno como externo, implica más bien un mayor debate respecto de las pertenencias culturales y los desplazamientos poblacionales de los individuos en el contexto de la globalización. Al abandonar su aquí-ahora para recuperar su allá-entonces, devienen significantes flotantes, desarticulados, ya que la recuperación del espacio no es suficiente para recobrar su estatuto original que corresponde a otro tiempo, al entonces. Como casos de estudios llamo la atención sobre los distintos testimonios y experiencias de vida que se hacen populares mediante las redes sociales. 


\section{Conclusiones}

- La racionalidad del wakcha héroe o migrante es de carácter mítico, ya que es heredero de una sabiduría ancestral que se enmarca en la cosmovisión andina.

- Debido a los distintos procesos de decantación simbólica que realiza el wakcha héroe o migrante en el nuevo espacio adonde se ha trasladado, sobre la base de sus propios códigos cognitivos pertenecientes a su racionalidad mítica, actualiza su estatuto de correspondencia respecto de la poderosa divinidad andariega de la tradición oral andina que corrige el orden cósmico que previamente ha sido alterado.

- El lugar de destino del desplazamiento poblacional constituye un criterio válido para clasificar la categoría del wakcha, ya que es precisamente en su lugar de destino donde será reempoderado para producir un pachacuty personal que alterará el aquí-ahora donde se ha asentado.

- Resulta problemática la figura del wakcha del retorno debido a que al volver a desprenderse de su aquí-ahora para regresar a lo que fue su allá-entonces, se acentúa su situación de extrañeza. En vez de conservar su estatuto de chakana que ha recobrado, más bien la vuelve a perder.

\section{Notas}

1 Para explicar el proceso de descubrimiento de la significación, Jaques Fontanille (2001) propone cuatro modos de aprehensión de la realidad o captaciones: la molar, la impresiva, la semántica y la técnica. A cada una de estas captaciones hace corresponder un determinado tipo de racionalidad: la racionalidad informativa, la hedónica, la mítica y la técnica, respectivamente.

2 En esta parte es conveniente indicar que para el objetivo del presente trabajo nos basamos en la propuesta de Josef Estermann (1998), respecto de lo que él ha denominado "filosofía andina". No nos detenemos a discutir su propuesta en términos filosóficos; más bien, consideramos su trabajo en tanto descripción de una forma de pensar fundamentada en lo que venimos denominando racionalidad mítica.

3 Cabe señalar que si bien estamos de acuerdo con gran parte de esta definición de la categoría runa, nos atrevemos a objetar un aspecto de esta y es el hecho de que Landeo restringe el concepto a las comunidades quechuahablantes. 
Nuestro argumento es de carácter histórico y antropológico, ya que la presencia del español en los Andes por más de cuatro siglos no ha sido obstáculo para que los mismos principios de la racionalidad mítica andina se sigan cultivando en las comunidades con pobladores andinos hispanoparlantes. Además, en la actualidad, existen, a lo largo del territorio nacional, comunidades campesinas enteramente conformadas por pobladores hispanohablantes que no han renunciado a sus costumbres ancestrales, lo que evidencia su racionalidad mítica. Por lo tanto, la constitución del wakcha abarcaría también a pobladores andinos hispanoparlantes, pero que mantienen una racionalidad mítica.

\section{Contribución del autor}

John Harvey Valle Araujo ha participado en la elaboración, la compilación de datos, la redacción y el consentimiento de la versión final del presente artículo.

\section{Fuente de financiamiento}

La investigación es autofinanciada.

\section{Conflictos de interés}

Ninguno.

\section{Trayectoria académica}

John Harvey Valle Araujo es licenciado en Literatura de la Facultad de Letras y Ciencias Humanas de la Universidad Nacional Mayor de San Marcos, en proceso de obtener el grado de magíster en Escritura Creativa en esta misma casa de estudios. Ha publicado Derroteros de la soledad: el wakcha en el relato andino de tradición oral (Lima, Ediciones Copé, 2013) y "Los recursos de la narración perturbadora como rasgos de referencialidad de la ficción narrativa" en el Boletín de la Academia Peruana de la Lengua (2019).

\section{Referencias bibliográficas}

Arguedas, J. (1961/1994). La soledad cósmica en la poesía quechua. En La literatura de ideas en América Latina (91-101). Colihue.

Bértoli, F. y Portocarrero, F. (1968). La modernización y la migración interna en el Perú. [Tesis de pregrado, Universidad Nacional Mayor de San Marcos].

Condori, B. y Gow, R. (1976). Kay pacha. Centro de Estudios Rurales Andinos "Bartolomé de las Casas". 
Contraloría General de la República. (CGR, 2014). Estudio del proceso de descentralización en el Perú. Lima: Contraloría General de la República.

Cornejo, A. (2004). Tradición migrante e intertextualidad multicultural: el caso de Arguedas. En W. Kapsoli (comp.), Zorros a fin del milenio. Actas y ensayos del seminario sobre la última novela de José María Arguedas (41-52). Universidad Ricardo Palma.

Cotari, D., Mejía, J. y Carrasco, V. (1978). Diccionario aymara-castellano y castellano-aymara. Instituto de Idiomas Maryknoll.

Chuquilin, J. (2011). La educación secundaria en Perú y sus profesores: cambios y continuidades. Educación, 35(2), 1-39. https://www.redalyc.org/ pdf/440/44021172005.pdf

Depaz, Z. (2014). Experiencia cósmica y dinámica social en el manuscrito de Huarochiri. Red Universitaria sobre Derechos Humanos y Democratización para América Latina, 3(5), 25- 41. https://docplayer.es/42125844-Experiencia-cosmica-y-dinamica-social-en-el-manuscrito-de-huarochiri.html

Estermann, J. (1998). Filosofía andina. Estudio intercultural de la sabiduría autóctona andina. Abya-Yala.

Fontanille, J. (2001). Semiótica del discurso. Fondo Editorial de la Universidad de Lima y Fondo de Cultura Económica.

Fuller, N. (2002). El papel de las clases medias en la producción de la identidad nacional. En N. Fuller (ed.), Interculturalidad y politica. Desafíos y posibilidades (419-440). Red para el Desarrollo de las Ciencias Sociales en el Perú.

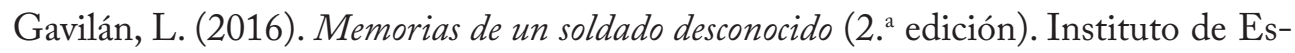
tudios Peruanos.

Golte, J. y Adams, N. (1990). Los caballos de Troya de los invasores: estrategias campesinas en la conquista de la gran Lima. Instituto de Estudios Peruanos.

González, D. (1608/ 1952). Vocabulario de la lengua general de todo el Perú llamada lengua qquichua o del inca. Universidad Nacional Mayor de San Marcos.

Instituto Nacional de Estadística e Informática y Organismo Internacional para las Migraciones (2015). Migraciones internas en el Perú a nivel departamental. Organismo Internacional para las Migraciones.Jameson, F. (1991). Ensayos sobre el posmodernismo. Imago Mundi.

Landeo, P. (2010). Categorias andinas para una aproximación al willakuy umallanchikpi kaqkuna (seres imaginarios del mundo andino). [Tesis de maestría, Universidad Nacional Mayor de San Marcos]. 
Lienhard, M. (2005). La cosmogonía poética en los waynos quechuas tradicionales. Acta Poética, 26(1-2), 485-513. http://dx.doi.org/10.19130/iill.ap.2005.12.180

Limachi, L. (2009). Procesos migratorios en la Amazonía peruana: una mirada a las migraciones internacionales. En L. Aragón (ed.), Migração Internacional Pan-Amazônia (197-113). NAEA/UFPA.

Lira, J. y Mejía, M. (2008). Diccionario quechua-castellano. Castellano-quechua. Universidad Ricardo Palma.

Mamani, M. (2019). Yanantin: relación, complementariedad y cooperación en el mundo andino. Estudios de Teoría Literaria. Revista digital: artes, letras y bumanidades, 8(16), 191-203. https://h.mdp.edu.ar/revistas/index.php/etl/article/view/3392

Marquez, F. y Corre, J. (2015). Identidades, arraigos y soberanías. Migración peruana en Santiago de Chile. Polis, Revista Latinoamericana, 14(42), 167-189. https://scielo.conicyt.cl/pdf/polis/v14n42/art_09.pdf

Matos, J. (2004). Desborde popular y crisis de Estado (veinte años después). Fondo Editorial del Congreso del Perú.

Montes, F. (1984). La máscara de piedra: Simbolismo y personalidad del aymara. Comisión Episcopal de Educación.

Morote, E. (1988). Aldeas sumergidas. Centro de Estudios Rurales Andinos "Bartolomé de las Casas".

Núñez, B. (junio de 1979). Yanantin: la dualidad andina. En A. Castelli (comp.), Simposium Ideología y Sociedad en los Andes. IV Congreso del Hombre y la Cultura Andina.

Organización Internacional para las Migraciones, Instituto Nacional de Estadísticas e Informática, Superintendencia Nacional de Migraciones, Ministerio de Relaciones Exteriores. (2018). Perú: Estadísticas de la Emigración Internacional de Peruanos e Inmigración de Extranjeros, 1990-2017. Organización Internacional para las Migraciones.

Platt, T. (1976). Espejos y maiz: temas de la estructura simbólica andina. Centro de Investigación y Promoción del Campesinado.

Prévôtel, A. (2016). Imitar el libro impreso. La Nueva corónica y las convenciones editoriales. Revista de Crítica Literaria Latinoamericana, XLII(84), 53-68. http://www.jstor.org/stable/44474254

Quispe-Agnoli, R. (2007). Prácticas indígenas de la resistencia: sujetos de la escritura 
y el saber en los Andes coloniales. Revista Iberoamericana, LXXIII(220), 415436. https://revista-eroamericana.pitt.edu/ojs/index.php/Iberoamericana/ article/view/5336/5493

Rodríguez, J. (2015). Determinantes de la migración interna y su incidencia en el nivel de vida de la población peruana: periodo 2000-2012. [Tesis de pregrado, Universidad Nacional de Trujillo].

San Román, J. (1994). Perfiles históricos de la Amazonía. CETA-CAAAP-IIAP.

Schlickers, S. (2015). La conquista imaginaria de América: crónicas, literatura y cine. Peter Lang.

Valle, J. (2013). Derroteros de la soledad: el wakcha en el relato andino de tradición oral. Ediciones Copé.

Yamada, G. (2012). Patrones de migración interna en el Perú reciente. En C. Garavito e I. Muñoz (ed.), Empleo y protección social (91-124). Fondo Editorial de la Pontificia Universidad Católica del Perú. 